\title{
Recognition of (Sesc) for Easy Identification of Staphylococcus Epidermidis and Molecular and Phenotypic Study of B-Lactam Resistance in Staphylococcus Epidermidis Isolates in Isfahan
}

\author{
Parisa Behshood $^{1}$, Elahe Tajbakhsh*1, Hassan Momtaz ${ }^{1}$
}

\begin{abstract}
Background: Not only is it crucial to rapidly detect Staphylococcus epidermidis (S. epidermidis) isolates from a broad range of bacteria, but recognizing resistance agents can greatly improve current diagnostic and therapeutic strategies.

Methods: The current cross-sectional study investigated 120 clinical isolates from a nosocomial S. epidermidis infection. The isolates were identified using common biochemical tests, and specific $S$. epidermidis surface protein C (SesC) primers were used to confirm the presence of $S$. epidermidis. PCR and special primers were used to detect the $\beta$-lactamase gene (blaZ). Methicillin resistance was measured using the agar screening method and antibiotic susceptibility was measured by disk diffusion.

Results: 100 samples were characterized as S. epidermidis using a phenotypic and genotypic methods. From the 100 specimens examined, $80 \%$ contained blaZ. According to agar screening, $60 \%$ of isolates were methicillin-resistant. S. epidermidis isolates demonstrated the highest resistance to penicillin (93\%) and the highest sensitivity to cefazolin (39\%).

Conclusions: The increased resistance to $\beta$-lactam antibiotics in S. epidermidis isolates is alarming, and certain precautions should be taken by healthcare systems to continuously monitor the antimicrobial pattern of S. epidermidis, so that an appropriate drug treatment can be established.
\end{abstract}

Keywords: Antibiotic resistance, $\beta$-lactam, Staphylococcus epidermidis.

\section{Introduction}

It is important to identify bacteria in clinics and medical diagnostic laboratories to provide appropriate therapeutic solutions (1). In most laboratories across the country, the identification process of isolates is based on phenotype or experimental biochemical test $(1,2)$.

Unfortunately, common biochemical tests are often Laborious and technical. The exact and definite diagnosis of isolates requires multiple tests that demand extensive preparation and isolated cultures (1). When the number of laboratory visits patients increases, it is practically impossible for everyone to provide and prepare media and other biochemistry tests, therefore, incomplete testing may occur. It actually reduces the required number of tests and the accuracy of identifying isolates by providing incorrect answers $(1,2)$. The biofilm interconnectedness and densification of gram-positive bacteria under a microscope are more complex than gram-negative bacteria. So that recognition of these bacteria based on morphology and biochemistry test is hard and time-consuming, and also some tests for them such as PYR and fermentation of different sugars, are not possible in laboratories due to their high cost $(1,2,5,18)$. Staphylococcus epidermidis (S. epidermidis) has 
become an important member of the coagulasenegative staphylococci (CNS) group within the last decade, is the third cause of nosocomial infections, and one of the most common causes of blood infections. $S$. epidermidis has been isolated from wound infections, skin infections, endocarditis, bacteremia, pneumonia, infected urinary tracts and soft tissue (1-4). The most important factor in the success of $S$. epidermidis stems from its ability to produce biofilm on the catheter. Today, $S$. epidermidis surface proteins have been found in biofilms, including $S$. epidermidis surface protein C $(\operatorname{Ses} C)$ and $S$. epidermidis surface protein I (SesI). The $\operatorname{Ses} C$ gene is necessary for biofilm creation and encodes for $\operatorname{Ses} C$, which contains 676 amino acids (2, 5). Anti-SesC antibodies are used to prevent the formation of biofilms caused by different strains of $S$. epidermidis, as these sequences are highly protected within this particular species $(1,5)$. Today, $\operatorname{Ses} C$ is used as a rapid identification marker for $S$. epidermidis from other isolates (2). $\beta$-lactam drugs are used to treat most $S$. epidermidis infections $(6,7)$. Resistance to $\beta$-lactam antibiotics is commonly associated with staphylococci resistance. This can be observed in hospital pathogens such as CNS (6). In staphylococci, the main mechanism of resistance against $\beta$-lactam antibiotics is generally divided into two categories $(6,8)$. The first category is characterized by the deactivation of penicillin by $\beta$ lactam ring hydrolysis. The second category, mostly observed in humans, includes the production of $\beta$-lactamase enzymes and penicillinbinding proteins (PBPs), both of which reduce the response to medication and increases resistance to semi-synthetic penicillin, cephalosporins, and carbapenems (9). A study conducted on the $\beta$-lactamase gene (blaZ) showed that it has structural, suppressor and signal transducer sequences coded by different blaZ groups (10). Not only does the secretion of the $\beta$ lactamase enzyme causes increased resistance to $\beta$ lactam drugs, but at high concentrations, some non-methicillin-resistant gene strains may confer false resistance to methicillin $(6,10,11)$. Methicillin-resistant isolates are created as a result of $S$. epidermidis conferring resistant genes, such as mecA. Often, this type of resistance leads to connects mecA gene or penicillin-binding protein
(PBP2' or PBP2a). This protein is a transpeptidase that has low attraction ability for $\beta$-lactams $(6,12)$. The resistance of the CNS group has been observed in both humans and animals $(6,13)$.

The identification of these pathogens is important to eliminate the development of hospital infections $(6,14)$. The aim of this study was to detect $\operatorname{Ses} C$ and blaZ in clinical specimens of $S$. epidermidis and determine resistance to methicillin and antibiotic susceptibility pattern of $\beta$-lactam drugs.

\section{Materials and methods}

\section{Sample collection and bacterial characterization}

In a span of six months, from January to June 2019, 120 clinical samples were collected and examined. The identification of isolates was conducted using common biochemical tests. The isolates were stored in brain heart infusion (BHI) media and $15 \%$ glycerol at $-20{ }^{\circ} \mathrm{C}$.

\section{Confirm of Staphylococcus epidermidis isolates}

To confirm the identity of strains, isolates were exposed to polymerase chain reaction (PCR) for the $S e s C$ gene. The genomic DNA of isolates was purified using a DNA extraction kit (CinnaGen, Iran) which was performed according to the manufacturer's protocol. Specific PCR primers used in this study can be found in Table 1. PCR was used to detect $S e s C$ which was previously described (2).

\section{Polymerase chain reaction for detection of blaZ}

PCR reaction was performed for detection of blaZ gene. DNA of the isolates were derived using DNA derivation kits according to the manufacturer's instructions (CinnaGen, Iran). The quality and quantity of DNA were determined using a spectrometer (Thermo Scientific, Waltham, MA, USA). Specific primer sequences were used to amplify blaZ (Table 1). The PCR protocol of this study followed the protocol described by Zehra et al (15). The PCR mixture was performed in a total volume of $25 \mu \mathrm{l}$. Primer sets containing blaZ $(1 \mu \mathrm{l}$ of each primer of $20 \mathrm{pmol}$ concentration) were added to the reaction volume. PCR cycling conditions included an initial denaturation step at $94{ }^{\circ} \mathrm{C}$ for $45 \mathrm{~s}$, followed by 30 cycles each of denaturation at $94{ }^{\circ} \mathrm{C}$ for $20 \mathrm{~s}$, then, annealing at $55^{\circ} \mathrm{C}$ for $15 \mathrm{~s}$ and extension at $70{ }^{\circ} \mathrm{C}$ 
for $15 \mathrm{~s}$, followed by a final extension step at $72{ }^{\circ} \mathrm{C}$

for 2 mins (15). Amplicons were stored at $4{ }^{\circ} \mathrm{C}$.

Table 1. Primer sequences used for PCR reaction.

\begin{tabular}{|c|c|c|c|}
\hline Size & Target gene & Sequence & Reference \\
\hline 388bp & SesC & $\begin{array}{l}\text { F: 5'- GTTGATAACCGTCAACAAGG -3' } \\
\text { R:5'CATGTTGATCTTTTGAATCCC-3' }\end{array}$ & (2) \\
\hline 173bp & blaZ & $\begin{array}{l}\text { F: 5'- ACT TCA ACA CCTGCTGCTTTC-3' } \\
\text { R:5'TGA CCA CTT TTA TCA GCA ACC -3' }\end{array}$ & (15) \\
\hline
\end{tabular}

\section{Resistance to methicillin (Agar screening method)}

For separation of isolates resistant to methicillin, agar screening method was used. For this purpose, after preparing of Muller Hinton agar Medium (Himedia, India) containing four percent salt, before distributing it on the plate, after the temperature of the autoclaved culture media reached about $45{ }^{\circ} \mathrm{C}$, the solution containing $6 \mu \mathrm{l} / \mathrm{mg}$ oxacillin (Sigma - Aldrich USA), was added to the autoclaved culture media by $0.2 \mu \mathrm{m}$ syringe filter. The bacterial suspension was prepared by previous incubation in BHI broth for $24 \mathrm{~h}$ and turbidity was set to equivalent to $0.5 \mathrm{McF}$ arland standard. After preparation of the bacterial suspension, $10 \mu \mathrm{l}$ suspension was seeded in spots on the agar surface with a swab and it was incubated for $24 \mathrm{~h}$ at $37{ }^{\circ} \mathrm{C}$. Finally, the separation of resistance isolates was according to the Clinical and Laboratory Standard Institute (CLSI) guidelines. Any growth on the medium was considered as a positive test outcome $(16,22)$.

\section{Antimicrobial susceptibility test}

Antibiotic susceptibility pattern of $\beta$-lactam drugs was performed using the Kirby-Bauer disk diffusion method. The following antibiotics were tested: Penicillin $(10 \mu \mathrm{g})$, Ceftriaxone (30 $\mu \mathrm{g})$, Amoxycillin $(10 \mu \mathrm{g})$, Cefoxitin $(30 \mu \mathrm{g})$, Cefotaxime $(30 \mu \mathrm{g})$, Cephalexin $(30 \mu \mathrm{g})$, and Cephazolin $(30 \mu \mathrm{g})($ Mast, $U K)$.

\section{Results}

Among the 120 specimens obtained from several different nosocomial infections, 100 samples were characterized as $S$. epidermidis following phenotypic analysis. All of the isolates were confirmed by SesC PCR (Fig. 1). Data introduced in Fig. 3 illustrates the distribution of S. epidermidis in various clinical specimens, and among the $100 \mathrm{~S}$. epidermidis isolates, the highest percentage of specimens were found in urine $(35 \%)$ and blood $(25 \%)$ samples and lowest percentage of specimens were found in lung (3\%) and eye (2\%) samples (Fig. 3).

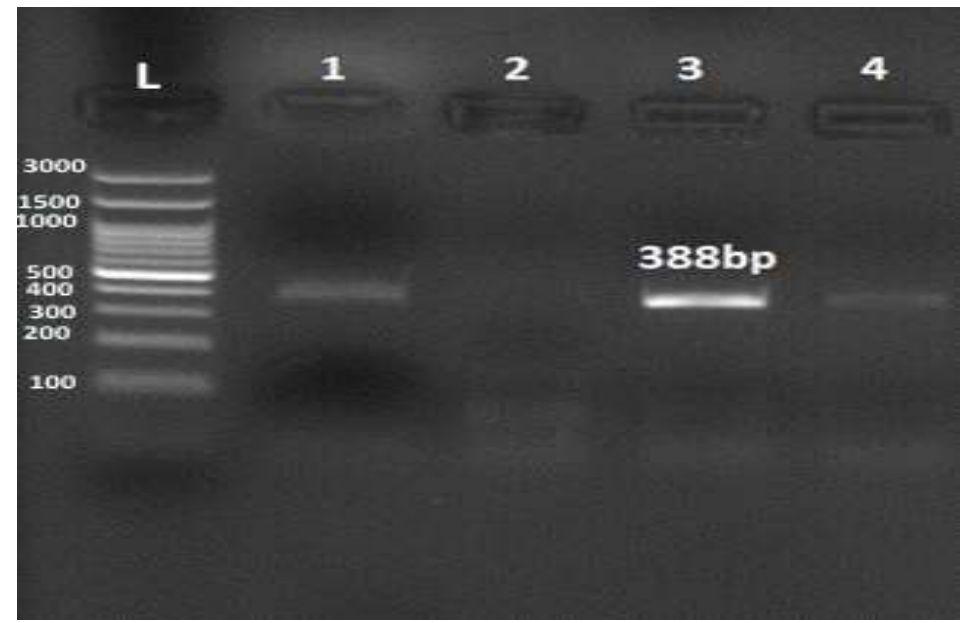

Fig. 1. SesC amplicon in PCR product of Staphylococcus epidermidis isolates. Lane L: Size marker (100 bp), Lane 2: Negative Control, Lanes 1, 3, and 4 (388 bp): Positive samples. 


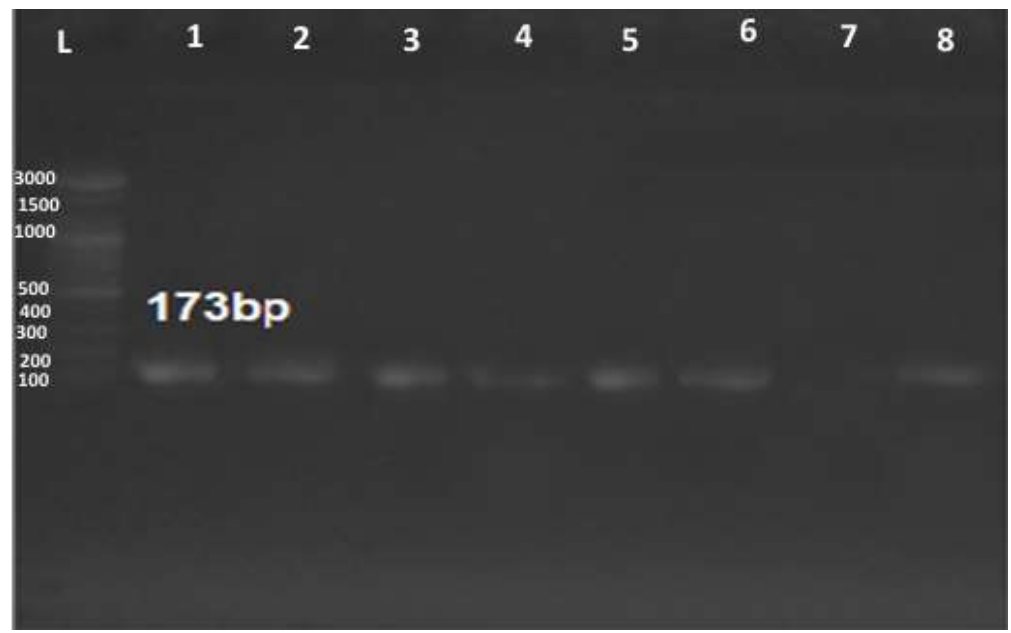

Fig. 2. blaZ amplicon in PCR product of Staphylococcus epidermidis isolates. Lane L: Size marker (100 bp), Lane 7: Negative Control, Lanes 1, 2, 3, 4, 5, 6, and 8 (173 bp): Positive samples.

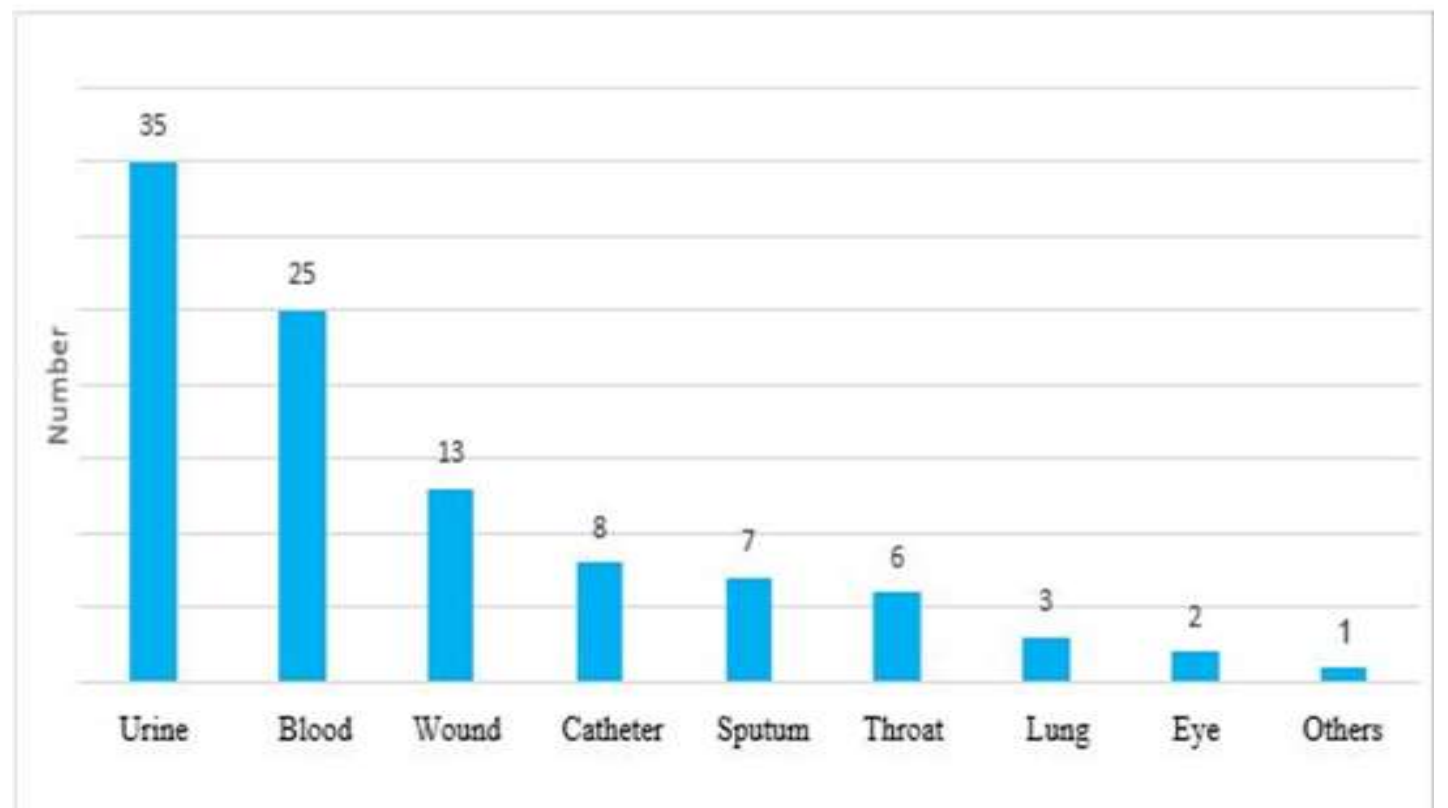

Fig. 3. Distribution of Staphylococcus epidermidis isolated from clinical samples.

Among the 100 specimens examined, 80 (80\%) samples contained blaZ (Fig. 2), and according to agar screening, $60 \%$ of the isolates were found to be methicillin-resistant. Furthermore, isolates showed higher resistance to penicillin (93\%) compared to ceftriaxone (85\%), and higher sensitivity to cephalexin (40\%) compared to Cephazolin (39\%) (Table 2).

Table 2. Antibiotic resistance pattern Staphylococcus epidermidis isolates to group of $\beta$-lactam antibiotics.

\begin{tabular}{lllllll}
\hline Antibiotic & No. of strains & Resistance (\%) & No. of strains & Semi resistance (\%) & No. of strains & Sensitivity (\%) \\
\hline Penicillin & 93 & 93 & 0 & 0 & 7 & 7 \\
Ceftriaxone & 85 & 85 & 0 & 0 & 15 & 15 \\
Amoxycillin & 80 & 80 & 10 & 0 & 10 & 10 \\
Cefoxitin & 65 & 65 & 0 & 0 & 35 & 35 \\
Cefotaxime & 50 & 50 & 2 & 2 & 48 & 48 \\
Cephalexin & 40 & 40 & 1 & 1 & 59 & 59 \\
Cefazolin & 39 & 39 & 4 & 4 & 57 & 57 \\
\hline
\end{tabular}




\section{Discussion}

Accurately identifying different strains of bacteria in laboratories has crucial implications in healthcare settings. The ability to rapidly recognize bacterial strains, while maintaining accuracy and simplicity, can improve current diagnostic approaches (2, 17). In this study, the $\operatorname{Ses} C$ gene was present in all $S$. epidermidis isolates. Therefore, the $\operatorname{Ses} C$ gene can be used as a genetic marker to distinguish $S$. epidermidis from other isolates (2). Khodaparast et al. (2016) reported $S e s C$ as a genetic marker that can easily identify $S$. epidermidis, since all of the $S$. epidermidis isolates contained SesC. Furthermore, the results of this study were consistent with our study $(5,18)$. Previous studies show that $60-85 \%$ of $S$. epidermidis isolates were methicillin-resistant in various geographical locations (12). Following an agar screen test, Shamansouri et al. (2016) reported that 68 out of $120 \mathrm{~S}$. epidermidis isolates were methicillin-resistant, similar to our findings (16). Among the 100 S. epidermidis isolates of the present study, the highest percentage of specimens were found in urine (35\%) and blood samples (25\%). Shamansouri et al. (2016) reported the highest isolation percentage of specimens in urine (77.94\%) but only $10.29 \%$ in the blood (16).

Additionally, Tahmasebi et al. (2016) found the highest percentage of isolates in the urine $(49.49 \%)$. Together, these two studies results align with our observations (6). The increased prevalence of resistance to $\beta$-lactam in $S$. epidermidis should be noted. In the present study, according to phenotype, $93 \%$ and $85 \%$ of S. epidermidis showed resistance to Penicillin and Ceftriaxone, and among the 100 specimens, 80 (80\%) contained blaZ, which is comparable to the outcome described by both Du et al. (England) and

\section{References}

1. Rahimi F, Mehmandoost J, danesh $\mathrm{m}$. misidentification of common pathogenic bacteria in a university hospital laboratory. 2016;21:49-54.

2. Fard SS, Amin M, Khodaparast L, Khodaparast L, Choghakabodi PM, Shahrooei M. Detection of biofilm phenotype of isolated Staphylococcus epidermidis from respiratory catheters of hospitalized patients and evaluation
Nahaei et al. (Iran). They reported a varying range of resistance to $\beta$-lactams in $S$. epidermidis, which is in agreement with our observations $(19,20)$. Tahmasebi et al. (2016) reported the highest resistance to Penicillin (85\%) and Ceftriaxone $(42.42 \%)$ and the least resistance to Ciprofloxacin (30.81\%) and Cephalexin (21.71\%). They also found that 149 specimens out of 198 specimens (75.25\%) contained blaZ. These results were similar to our observations (6). Raei et al. (2007) reported the highest resistance to Penicillin (98.1\%), Methicillin (90.9\%), Ceftriaxone $(52.7 \%)$ and Ceftizoxime (49.09\%), and the lowest to Cephazolin (30.9\%), Cephalexin (23.6\%). Furthermore, an iodometric test showed that all of the isolates were $\beta$-lactamase producers and, moreover, PCR analysis confirmed the presence of blaZ in all isolates. Although the antibiotic resistance pattern was similar to our findings, the results of blaZ, however, differed (21). The propagation of resistant isolates to various $\beta$-lactam antibiotics is on the rise. Therefore, the therapy of infections related to $S$. epidermidis infections requires a definite and accurate diagnosis. Ultimately, we can prevent the unnecessary use of prescribed antibiotics by developing rapid, and more accurate treatments.

\section{Acknowledgment}

The present article is the result of Elahe Tajbakhsh' Ph.D. thesis numbered 940434128, Shahrekord Azad University. We gratitude Dr. Sepideh Karimi, for her continued friendship and noetic contributions during this survey.

No conflict of interest was announced by the authors.

the effect of antibodies against $\operatorname{Ses} C$ protein on biofilm formation. Clinical Microbiology: Open Access. 2015.

3. Järvinen A-K, Laakso $\mathrm{S}$, Piiparinen $\mathrm{P}$, Aittakorpi A, Lindfors M, Huopaniemi L, et al. Rapid identification of bacterial pathogens using a PCR-and microarray-based assay. BMC microbiology. 2009;9:161. 
4. Kasavandi A, BikhofTorbati M, Amini K. Molecular Detection of Staphylococcus aureus, $S$. epidermidis, and $S$. hominis Isolated from the Neonatal Umbilical Cord by Multiplex PCR Method. J Ardabil Uniof Med Sci. 2018;18(3):377-386.

5. Khodaparast L, Khodaparast L, Shahrooei M, Stijlemans B, Merckx R, Baatsen P, et al. The possible role of Staphylococcus epidermidi LPxTG surface protein $S e s C$ in biofilm formation. PLoS One. 2016;11(1):e0146704.

6. Tahmasebi h, bokaeian m, adabi j. Phenotypic and molecular study of beta-lactam resistance in coagulasenegative staphylococci samples. 2016:55-53.

7. Dehghani A, Gholipour A, Nazari-Vanani R, Heibati F. Molecular investigation of methicillinresistant Staphylococcus epidermidis and Staphylococcus saprophyticus isolated in Shahrekord training hospitals. J Shahrekord Uuniv Med Sci. 2015;17(2):93-104.

8. Becker K, Heilmann C, Peters G. Coagulasenegative staphylococci. Clinical microbiology reviews. 2014;27(4):870-926.

9. Bush K. Past and present perspectives on $\beta$ lactamases. Antimicrobial agents and chemotherapy. 2018;62(10).

10. Xu Z, Mkrtchyan HV, Cutler RR. Antibiotic resistance and mecA characterization of coagulase-negative staphylococci isolated from three hotels in London, UK. Front Microbiol. 2015;6:947.

11.Martins A, Riboli DFM, Camargo CH, Pereira VC, de Almeida Sampaio R, de Souza MdLR. Antimicrobial resistance and persistence of Staphylococcus epidermidis clones in a Brazilian university hospital. Diagnostic microbiology and infectious disease. 2013;77(2):164-168.

12. Razavi S, Dadashi M, Pormohammad A, Khoramrooz SS, Mirzaii M, Gholipour A, et al. Methicillin-resistant staphylococcus epidermidis in Iran: A systematic review and meta-analysis. Arch Clin Infec Dis. 2018;13(4):e58410.

13. Feßler AT, Billerbeck C, Kadlec K, Schwarz $\mathrm{S}$. Identification and characterization of methicillin-resistant coagulase-negative staphylococci from bovine mastitis. J Antimicrob Chemother. 2010;65(8):1576-82.
14. Park JY, Fox LK, Seo KS, McGuire MA, Park YH, Rurangirwa FR, et al. Comparison of phenotypic and genotypic methods for the species identification of coagulase-negative staphylococcal isolates from bovine intramammary infections. Vet microbiol. 2011;147(1-2):142-8.

15. Zehra A, Singh R, Kaur S, Gill J. Molecular characterization of antibiotic-resistant Staphylococcus aureus from livestock (bovine and swine). Vet world. 2017;10(6):598-604.

16. Shamansouri S, Karbasizade V, Khozaie M. Determining Sccmec Types In Staphylococcus Epidermidis Isolated From Clinical Samples Of Ishahan, Iran. Acta Medica Mediterranea. 2016;32:2107-2113.

17. Kitti T, Seng R, Saiprom N, Thummeepak R, Chantratita N, Boonlao C, et al. Molecular Characteristics of Methicillin-Resistant Staphylococci Clinical Isolates from a Tertiary Hospital in Northern Thailand. Can J Infect Dis Med Microbiol. 2018:8457012.

18. Khodaparast L, Khodaparast L, Van Mellaert L, Shahrooei M, Van Ranst M, Van Eldere J. sesC as a genetic marker for easy identification of Staphylococcus epidermidis from other isolates. Infect Genet Evol. 2016;43:222-4.

19. Nahaei MR, Shahmohammadi MR, Ebrahimi S, Milani M. Detection of methicillin-resistant coagulase-negative staphylococci and surveillance of antibacterial resistance in a multi-center study from Iran. Jundishapur J Mic. 2015;8(8):e19945.

20. Du X, Zhu Y, Song Y, Li T, Luo T, Sun G, et al. Molecular analysis of Staphylococcus epidermidis strains isolated from community and hospital environments in China. PloS one. 2013;8(5):e62742.

21. Raei F, Eftekhar F. Studying the presence of blaZ gene and $\beta$-lactamase production in clinical isolates of Staphylococcus epidermidis. Iran J Med Microbiol. 2008;2(2):35-41.

22.Akbariyeh H, Nahaei MR, Hasani A, Pormohammad A. Intrinsic and Acquired Methicillin-Resistance Detection in Staphylococcus aureus and Its Relevance in Therapeutics. Archives of Pediatric Infectious Diseases. 2017;5(1):e39185. 